\title{
A espiritualidade de Jesus: mística, profecia e sabedoria
}

\section{Lúcia Pedrosa-Pádua ${ }^{1}$}

Na espiritualidade cristã, mística, sabedoria e profecia não se separam, como nos faz ver a forma de ser e viver de Jesus de Nazaré. Observando os Evangelhos vemos como, em Jesus, estas três dimensões se exigem e enriquecem mutuamente. Por isso, no seguimento do Mestre, cada cristão também testemunha a mística-sabedoria-profecia. Pela mística, nasce uma nova relação com Deus; pela sabedoria, são tecidas formas de viver e de se relacionar de maneira mais humanizada, segundo a lógica de Deus (cf. Mc 8,33); pela profecia, a Igreja e a sociedade são dotadas de opções ousadas e transformadoras, dignas da Palavra geradora de Deus no mundo.

Olhemos para a espiritualidade de Jesus.

\section{Jesus, o profeta}

Iniciemos com a dimensão profética de Jesus, pois sabemos, pelos Evangelhos, que ele foi reconhecido como profeta e assim se via a si próprio. Ele mesmo disse que "nenhum profeta é bem acolhido em sua própria pátria" (Lc 4,24). Como profeta, Jesus ${ }^{2}$ :

- falou claramente, criticando o seu próprio país, sociedade e mesmo instituições religiosas em suas contradições e infidelidades ao projeto de amor e justiça de Deus;

\footnotetext{
${ }^{1}$ Lúcia Pedrosa-Pádua é doutora em teologia sistemática pela PUC-Rio, onde é pesquisadora e professora em tempo contínuo. Atua nas áreas de Antropologia Teológica, Mariologia e Espiritualidade. Graduada em teologia pela Faculdade Jesuíta de Filosofia e Teologia (Belo Horizonte, MG) e em Economia pela UFMG. Coordena o Ataendi, Centro de Espiritualidade da Instituição Teresiana no Brasil, dedicado à formação de cristãos leigos e leigas e trabalha na ação pastoral junto a comunidades.
}

2 Cf. NOLAN, A. Jesus Hoje: uma espiritualidade de liberdade radical. São Paulo: Paulinas, p. 101-107. 
- soube ler os sinais dos tempos e, ao contrário dos líderes religiosos, soube perceber a situação dos trabalhadores do campo e das cidades e o sofrimento dos pobres que empobreciam a cada dia; e nisso não foi ingênuo;

- teve consciência da tensão e conflito que provocava. Mas este conflito é vivido como bem-aventurança: "felizes sereis quando vos odiarem e rejeitarem" (Lc 6,22-23).

- teve também consciência do destino incompreendido e violento dos profetas (cf. Mt 23,29-35).

Jesus é, assim, um homem em constante e audaz missão, a serviço dos demais. Seus seguidores aprendem, como seu Mestre, a falar e a agir com ousadia.

\section{Jesus, o místico}

O Jesus místico é tão forte quanto o Jesus profeta. Os evangelhos nos mostram como sua atividade e missão são sustentadas por uma experiência única daquele que ele chamava de Abbá - Pai. A relação de Jesus com o Pai se dá através de constante oração e de profunda contemplação. Jesus rezava porque necessitava, de fato, da luz, da força e do discernimento que vem de Deus. ${ }^{3}$

Os discípulos viram Jesus frequentemente em oração. Às vezes, ele se afastava para rezar. Textos bíblicos indicam que Jesus aproveitava todas as oportunidades possíveis para retirar-se e entregar-se à oração e à reflexão (Mc 1,35; 6,46; Lc 4,$42 ; 11,1 ; 22,41 ;$ Mt 14,23; 26,36). E o fazia com regularidade, pois Lucas observa que ele "permanecia retirado em lugares desertos e orava" (Lc 5,16). Além disso, Jesus recomendou a oração na intimidade do quarto, não como os

\footnotetext{
${ }^{3}$ Para o tema da oração de Jesus, cf. AZEVEDO, M. A oração na vida: desafio e dom. São Paulo: Loyola, 1988, p.117-133; ESPEJA, J. Espiritualidade Cristã. Petrópolis: Vozes, 1995, p. 341-357; GARCIA RUBIO, A. O Encontro com Jesus Cristo vivo. 14를 ed., São Paulo: Paulinas, 2010, p. 86-88; NOLAN., op. cit., p.107-117; PAGOLA, J.A. Jesus. Aproximação histórica. Petrópolis: Vozes, 2010, p. 363-398.
} 
hipócritas que gostam de ser vistos pelos outros (cf. Mt 6,5-6). Assim, podemos estar certos de que Jesus passava muito tempo rezando em lugar oculto.

A oração de Jesus é vivida em relação com os acontecimentos mais significativos de sua vida. Segundo os evangelhos, Jesus orou:

- depois de seu batismo (Lc 3,21);

- no início de sua missão (Lc 4,1);

- em dias de intensa atividade (Mc 1,35; Lc 5,16; Mt $14,23)$;

- antes de vários momentos significativos, como a eleição dos apóstolos (Lc 6,12), a profissão de Pedro (Lc 9,18), a oração do Pai-Nosso (Lc 11,1), a ressurreição de Lázaro (Jo 11,41), sua paixão e morte (Jo 17,1-26).

Jesus orou no acontecimento da transfiguração (Lc 9,28-29); no Getsêmani, antes de sua morte (Mt 26,36-44; Mc 14,32-34; Lc 22,32.41.44); na cruz, em que oferece o perdão e entrega sua vida (Mc 15,34; Mt 27,46; Lc 23,34.46).

Sua oração estava vinculada à sua vida e à sua missão, sem fuga ou alienação. Oração e vida se fecundam mutuamente, a oração está relacionada à missão e esta com a oração. Jesus passou por situações de alegria, ânimo, êxito e aclamação, mas também por duros momentos de dificuldade, crise, fracasso e perseguição até a morte. Em todos estes momentos está presente a oração, sempre como um diálogo, como relação pessoal com Deus-Ágape, gratuito e próximo. ${ }^{4}$

A oração que melhor traduz a relação de Jesus com o Pai é o Pai-Nosso (Mt 6, 9-12; Lc 11, 1-3). Ela é também o modelo de nossa oração. Nela, Jesus ensina a chamar a Deus de Abbá, que poderia ser traduzido como paizinho. Ela revela

${ }^{4}$ Cf. GARCIA RUBIO, A. op.cit., p. 81-86. 
a relação próxima e de total confiança de Jesus com seu Pai. Os discípulos se lembram de ver Jesus se dirigindo a Deus com esta palavra familiar e que ele os ensinava a fazer o mesmo. Por uma palavra pouco convencional, foi conservada no NT no original aramaico: “Abbá-Pai” (Mc 14,36; Gl 4,6; Rm $8,15)$.

Esta relação entre Jesus e o Pai é a fonte da sabedoria, discernimento, confiança e liberdade de Jesus, sem a qual não é possível compreender o seu amor para com todos, inclusive aos inimigos, e o porquê de suas ações.

O centro da oração que Jesus ensina, o Pai Nosso, é o Reino de Deus, que pedimos e com o qual nos comprometemos com o perdão e a partilha do pão. Mas Jesus faz sérias críticas a formas de oração que não levam ao Reino. Aquela oração sem coerência de vida (Mt 6, 5); mecânica, sem compromisso, que multiplica palavras (Mt 6,7); separada do acolhimento concreto da vontade de Deus (Mt 7, 21-23: "não basta dizer Senhor, Senhor..."). A oração arrogante e cheia de autocontemplação (Lc 18, 11-12) não estabelece um diálogo de abertura ao dom de Deus, ao contrário, reforça o fechamento do ser humano em si mesmo. Leva ao narcisismo e ao autoengano. A verdadeira relação com Deus, ao contrário, recria as relações fundamentais do ser humano: com Deus, consigo mesmo, com os irmãos e com a natureza.

Na vida de Jesus, mística e profecia se unem de uma forma extraordinariamente simples. Um todo inseparável. Por isso, denominar a tradição espiritual cristã como tradição místico-profética é uma forma de ultrapassar os antagonismos do passado e de hoje. Algumas pessoas pensam que a oração não tem relação alguma com as atitudes e formas de atuar, mas os evangelhos nos mostram o contrário. A oração fecunda uma vida que busca amar concretamente e que opta pela justiça, especialmente aquela relativa aos pobres e aos excluídos. 


\section{Jesus, o sábio}

A esta mística-profecia, devemos unir a sabedoria. Jesus é mestre de sabedoria. ${ }^{5}$ É um sábio. O Evangelho de Mateus manifesta este reconhecimento. Diante dos ensinamentos de Jesus, os ouvintes perguntam admirados: "Donde lhe vem esta sabedoria?" (Mt 13,54). Jesus não apenas se expressa como os sábios, ele vai mais além, pois nele a sabedoria de Deus se manifesta. Lemos em Mt 11,28-30: "Vinde a mim, todos vós que estais cansados sob o peso do fardo, e eu vos darei descanso. Tomai sobre vós o meu jugo, e sede discípulos meus, porque eu sou manso e humilde de coração, e encontrareis descanso para as vossas almas. Sim, o meu jugo é fácil de carregar e o meu fardo é leve”. Ora, no Livro do Eclesiástico (51,23-29) encontramos palavras semelhantes, atribuídas à Sabedoria. Jesus, por sua vez, se expressa em primeira pessoa: "vinde a mim". Isto nos mostra porque, para a fé cristã, Jesus mesmo é a sabedoria vinda de Deus.

A sabedoria de Jesus orienta o bem viver segundo os critérios do Reino de Deus. Ela penetra o cotidiano da vida e das relações sociais de forma de humanizar a convivência, dar sentido às atividades, ajudar a amar com paciência e perdão, viver o cotidiano sem medir as pessoas pelo resultado, ensinar a servir, ser bom e confiar.

Uma atitude de escuta e de prática deve caracterizar o seguidor de Jesus. Especialmente os que governam devem se imbuir desta sabedoria: mães, pais, mestres, grupos, governantes. O estilo pedagógico de Jesus faz parte de sua sabedoria. Ele parte da vida cotidiana, como podemos encontrar nas parábolas. Estas falam de pastor e de ovelhas, de

${ }^{5}$ Cf. GILBERT, M. Sabiduría. In: ROSSANO, P. et al. (dir.). Nuevo Diccionario de Teología Bíblica. Madrid: Paulinas, 1990, p. 1711-1728 e BRITO, Jacil Rodrigues. Faça de sua casa um lugar de encontro de sábios. São Paulo: Paulinas, 2011. 
videiras, de compra e venda, de moeda perdida, de casa a ser construída, de tesouro a empregar... Os personagens são um rei, um pai, um filho, um empregado, um senhor, uma dona de casa... Referem-se à vida rural e do campo. Muitos discursos de Jesus também apresentam um perfil sapiencial, orientam a vida e as relações humanas e comunitárias, como o sermão da montanha (Mt 5-7) ou o discurso do pão da vida (Jo 6). Como os sábios, Jesus se expressa através de máximas, conselhos e exortações (cf. Mt 26,52; Mt 16,25; At 20,35; Mc 9,40; Mt 8,22 ; Mt 22,21 etc).

O apóstolo Paulo, por sua vez, coloca em evidência que a sabedoria de Deus é manifestada em Cristo crucificado (1Cor 1,23-24). Ressalta como a lógica do Reino trazido por Jesus contradiz a lógica das pretensões humanas. Por isso, a sabedoria do Reino é considerada loucura por uns e escandaliza outros. No entanto é esta, não outra, a sabedoria de Deus!

\section{A separação errônea acontecida na história}

$\mathrm{Na}$ história das religiões, não faltaram análises que privilegiaram a contraposição entre mística e profecia. Separavam, inclusive, as religiões proféticas das religiões místicas. ${ }^{6}$ A profecia foi associada à afirmação da pessoa, do mundo e da história; a mística, à negação destas realidades. Segundo este dualismo:

- a profecia propõe uma transformação do mundo, enquanto a mística tende à fuga;

- a profecia propicia uma relação histórica com Deus, enquanto a mística vive uma experiência ahistórica;

- a profecia é ativa e evangelizadora, enquanto a mística é passiva e contemplativa, sem ação.

${ }^{6}$ Cf. MARTIN VELASCO, Juan. El fenómeno místico. Estudio comparado. Madrid: Trotta, 1999, p. 25-28. 
Esta contraposição atingiu inclusive a relação da mística com a ética. ${ }^{7}$ Segundo esta contraposição, haveria pessoas que encarnam ou uma coisa ou outra, como se fossem duas formas diferentes e incompatíveis de realização da existência humana. A ética ou moral estaria ligada ao dever, ao esforço, à vontade de atitude e compromisso. A mística se relacionaria à passividade e gratuidade, ao entusiasmo, ao êxtase e à despreocupação com o que se encontra ao redor. Contraposição que figura como um dos tantos dualismos fortemente enraizados em nossa cultura, de raízes platônicas e neoplatônicas. ${ }^{8}$ Algumas tendências místicas também ajudaram nesta contraposição.

Mas estas contraposições têm escasso fundamento. Vimos como a espiritualidade de Jesus é místico-proféticasábia, inter-relacionadas de maneira extraordinariamente simples e integrada.

\section{Concluindo}

O convite de trilhar o mesmo caminho de Jesus continua aberto. Cada cristão e cristã é chamado a viver integradamente:

- a mística, como um estar em relação com o mistério de Deus, cuja Encarnação engloba o mistério de cada um, do mundo e da natureza;

- a sabedoria, como arte de discernir os caminhos de Deus tanto no ser e viver cotidianos, de tal forma que o modo de ser de Jesus, que foi contracorrente, questione o mundo consumista, individualista e indiferente e crie formas mais sábias e solidárias de viver;

${ }^{7}$ Cf. MARTIN VELASCO. El fenómeno místico, p. 457-466.

8 GARCIA RUBIO, Alfonso. Unidade na pluralidade. O ser humano à luz da fé e da reflexão cristãs. $4^{\mathrm{a}}$ ed., São Paulo: Paulus, 2006, p. 95-114. 
- a profecia, como fogo que não deixa calar e que, em tempos difíceis, abre, com audácia, caminhos do mundo novo que Deus deseja.

Sejamos místicos, sábios e profetas. Assim poderemos também sonhar com a humanização do mundo pelas mãos de Deus.

\section{Bibliografía}

AZEVEDO, Marcelo. A oração na vida: desafio e dom. São Paulo: Loyola, 1988.

BRITO, Jacil Rodrigues. Faça de sua casa um lugar de encontro de sábios. São Paulo: Paulinas, 2011.

ESPEJA, Jesús. Espiritualidade Cristã. Petrópolis: Vozes, 1995.

GARCIA RUBIO, Alfonso. O Encontro com Jesus Cristo vivo. 14ª ed., São Paulo: Paulinas, 2010.

luz da fé e da reflexão cristãs. $4^{a}$ ed., São Paulo: Paulus, 2006.

GILBERT, M. Sabiduría. In: ROSSANO, P. et al. (dir.). Nuevo Diccionario de Teología Bíblica. Madrid: Paulinas, 1990, p. 1711-1728.

MARTÍN VELASCO, Juan. El fenómeno místico. Estudio comparado. Madrid: Trotta, 1999, p. 25-28.

NOLAN, Albert. Jesus Hoje: uma espiritualidade de liberdade radical. São Paulo: Paulinas, p. 101-107.

PAGOLA, José Antonio. A. Jesus. Aproximação histórica. Petrópolis: Vozes, 2010.

PEDROSA-PÁDUA, Lúcia. Mística e profecia na espiritualidade cristã. O testemunho de Santa Teresa de Jesus. Horizonte, Belo Horizonte, v. 10, n. 27, p. 757-778, jul./set. 2012. Acessível em http://periodicos.pucminas.br/index.php/horizonte/article/view 


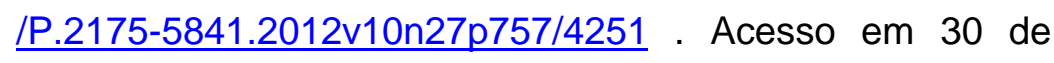
junho de 2018.

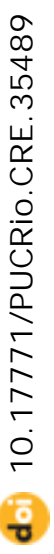

